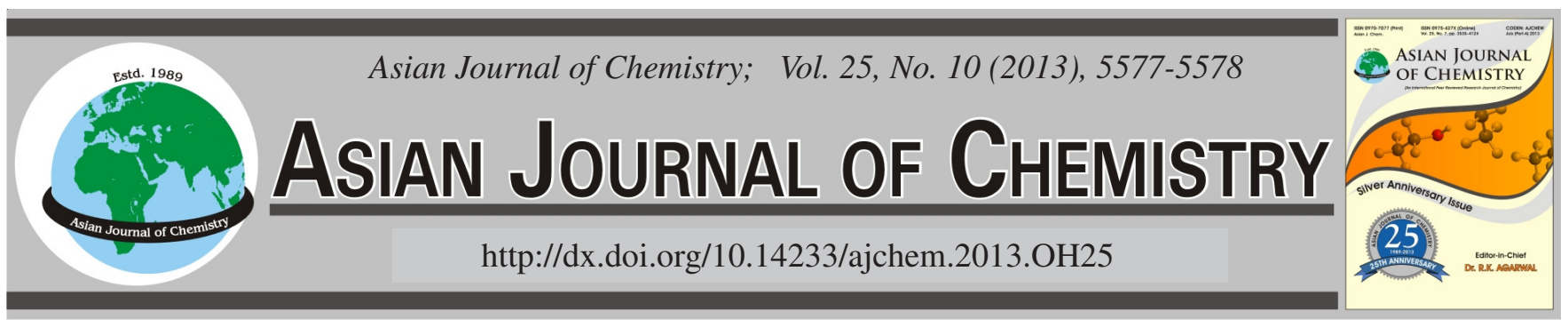

\title{
Research on the Wear Resistance of Wear-Resistant Materials $\dagger$
}

Hongzheng Zhu*, Yin Liu, Jingo Zhu and Chuanchuan Cai

School of Materials Science and Engineering, Anhui University of Science and Technology, Huainan 232001, P.R. China

*Corresponding author: E-mail: zhang-fengjun@hotmail.com

Test is the traditional research method of the wear resistance of wear-resistant materials, but it is complex and complicated. Now a new
method, which is described clearly with a industrial example, is put forward. With the new method, the number of the jet impact force can
be simulated by GAMBIT and FLUENT. The study is significant for the optimization of the characteristic of the wear-resistant materials
and the structure of the device.
Key Words: Wear-resistant material, Simulate, Wear, Attack. ᄂ - - - - - - - - - - - - - - - - - - - - - - - - - -

\section{INTRODUCTION}

The history of wear-resistant material is long and the rapid development make it the core of the new material field ${ }^{1-3}$. Wearresistant material advances and supports the development of high and new technology, and its share of the area of global research on new materials is high ${ }^{4-8}$. Due to the special properties of wear-resistant material, its use in the engineering field is rising year by year. Now wear-resistant steel material is the most widely used and maximum consumed of wear-resistant materials ${ }^{9}$.

We often find that wear-resistant steel material is worn heavily by the attack of high-pressure jet flow in the engineering field, but the pressure of wear-resistant steel material sustains can not be measured easily, that hampers the development of wear-resistant steel material greatly.

\section{EXPERIMENTAL}

The FJC series flotation machines (Fig. 1) are widely used in coal preparation plants currently. Fluid flow into the work tank form the inlet orifice at $0.015 \mathrm{MPa}$, and flow along the broken line in the pipeline. At last, fluid flow out of the pipeline from the outlet orifice, and attack the wear-resistant steel material at the bottom of the work tank at high speed, wear the general steel material heavily. So, the number of the jet impact force is both useful for the optimization of the wearresistant steel material and the choice of the more suitable material to make the bottom of the work tank.

When the device is running, the tank will be filled with fluid. Then it is difficult to test the number of the jet impact force by the common pressure test methods, but we can simulate the pressure value by the computational fluid dynamics software.

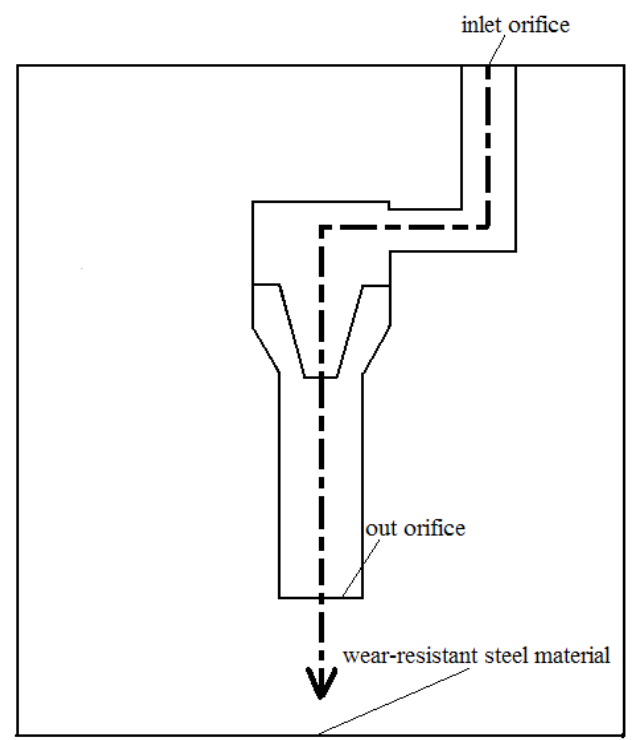

Fig. 1. Model diagrammatic figure

\section{RESULTS AND DISCUSSION}

Computational fluid dynamics (CFD) based on mathematical analysis and theoretical fluid mechanics, with the computer technology and numerical computation technology as the tools, can simulates the correct or approximate solution of the flow field control equation and it is an applied subject. 
Compared with hydromechanics test, computational fluid dynamics is low-cost, high-efficiency and high-fidelity. Computational fluid dynamics provides theoretical direction for exploratory research on flow field. Now during the computational fluid dynamics commercial software, such as GAMBIT, FLUENT and so on are commonly used.

According to the size of the device, a three-dimensional finite element model the same with the device is established by GAMBIT, as shown in Fig. 2.

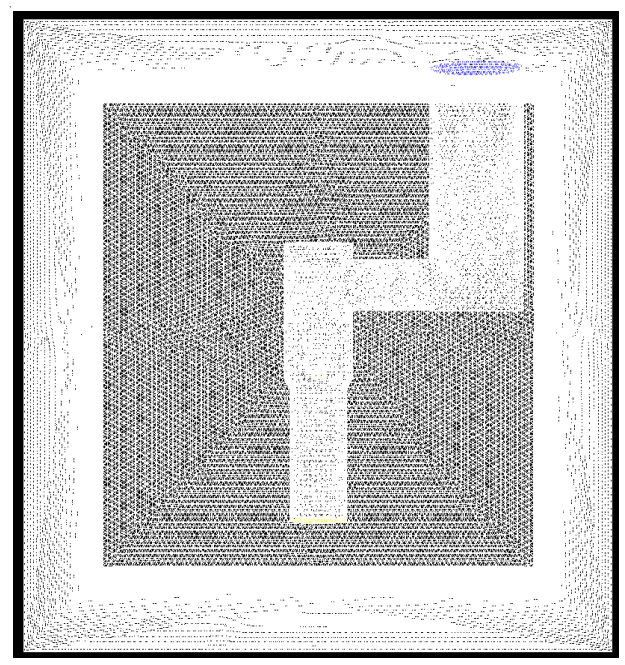

Fig. 2. Model mesh generation figure

The model consists of 1.11 million body units or 2.25 million surface units. We import the three-dimensional finite element model to FLUENT, and set the conditions as the following: the inlet orifice set for pressure-inlet, and pressure at $0.15 \mathrm{MPa}$; turbulence model set for the $\mathrm{k}-\varepsilon$ model; phase set for water; continuous equation and momentum equation set for SIMPLEC algorithm coupled pressure-speed; convection term set for the first order upwind; residual set for the fifth order convergence; set a monitor points at the bottom enfilade the outlet orifice, and monitor the pressure value of the point, get the number of the jet impact force (Fig. 3).

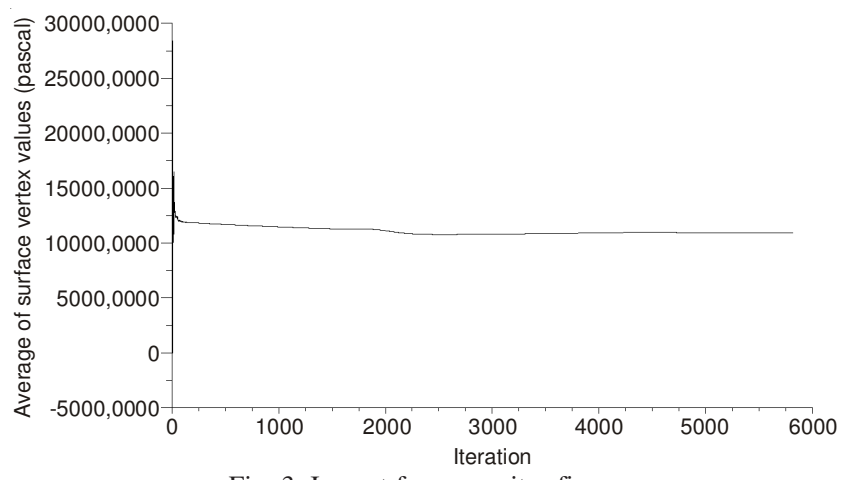

Fig. 3. Impact force monitor figure
From the simulate results, we can see that the attack pressure on the wear-resistant steel material at the bottom of the tank is about $0.012 \mathrm{MPa}$, but the model of the wearresistant steel material is Q235-A. Q235-A contains $\mathrm{C}(0.22$ $\%), \mathrm{Si}(0.35 \%), \mathrm{Mn}(1.4 \%), \mathrm{P}(0.045 \%)$ and S (0.045 \%), its thickness is about $12 \mathrm{~mm}$, its maximum yield strength is 235 $\mathrm{N} / \mathrm{mm}^{2}$ and its hardness is below HRC10, so it was worn heavily by the attack of high-pressure jet flow about $0.012 \mathrm{MPa}$.

Based on the characteristics of the commonly used wearresistant materials and the number of the high-pressure jet flow, we can choose some suitable wear-resistant materials to replace Q235-A for making the bottom of the tank, as the follows:

1. NM500, HBW: 480-525

2. WNM360A, HRC: 58-62

\section{Conclusion}

In summary, the number of the jet impact force attacked the wear-resistant steel material was successfully simulated by hydrodynamics software GAMBIT and FLUENT. Based on the characteristics of the commonly used wear-resistant materials and the number of the high-pressure jet flow, some suitable wear-resistant materials were chosen to make the bottom of the tank, which is significant for the optimization of the characteristic of the wear-resistant materials and the structure of the device.

\section{REFERENCES}

1. V. Abdrakhimov, Refract. Ind. Ceram., 1, 52 (2010).

2. R. Batienkov, V. Dorofeev, Zh. Eremeeva and V. Artemov, Metallurgist, 3, 289 (2011).

3. A. Zholud, A. Derbyshev and Yu. Dulepov, Chem. Petrol. Eng., 9, 627 (2011).

4. Y.S. Lerner and G.R. Kingsbury, J. Mater. Eng. Perform., 1, 48 (2007).

5. I.D. Radomysel'skii and E.V. Rymorov, Powder Metall. Metal Ceram., 10, 780 (2004).

6. V.A. Maslyuk and S.G. Napara-Volgina, Powder Metall. Metal Ceram., 9, 521 (2007).

7. Genadii A. Baglyuk and L.A. Posnyak, Powder Metall. Metal Ceram., 3, 174 (2004).

8. V.V. Fadin, A.V. Kolubaev, V.I. Koveshnikov and S.P. Batalov, Chem. Petroleum Eng., 12, 733 (2005).

9. M.S. Koval'chenko, N.N. Sereda, V.I. Ostroverkhov and I.T. Belik, Powder Metall. Metal Ceram., 12, 993 (2004). 